\title{
DESAFIOS E TRAJETÓRIA ESCOLAR DE UM ESTUDANTE COM ALTAS HABILIDADES/SUPERDOTAÇÃO
}

\author{
CHALLENGES AND EDUCATIONAL PATH OF A STUDENT \\ WITH HIGH SKILLS/INTELECTUAL GIFTEDNESS \\ DESAFÍOS Y TRAYECTORIA ESCOLAR DE UN ESTUDIANTE \\ CON ALTAS HABILIDADES /SUPERDOTACIÓN
}

\author{
Michelle Maia Mendonça ${ }^{\mathrm{I}}$ \\ Carla Cristine Tescaro S. Lino \\ Diogo Janes Munhoz ${ }^{I I I}$ \\ 'Universidade Estadual do Norte do Paraná (UENP), Jacarezinho/PR - Brasil \\ "Universidade Estadual Paulista (UNESP), Marília/SP - Brasil \\ IIIUniversidad Columbia, Assunção - Paraguai
}

Resumo Trata-se de um estudo de caso sobre a necessidade de identificação e flexibilização curricular ao estudante que apresenta características de altas habilidades/superdotação (AH/SD). O estudante participante dessa pesquisa reside e estuda em uma cidade localizada no interior do estado do Paraná, e foi identificado como Bob, para preservar sua identidade. Analisar o trabalho pedagógico com o estudante e se os professores se encontravam preparados para identificarem estudantes superdotados em sala de aula, se tornou a problemática dessa pesquisa. Objetivou-se, portanto, apresentar os desafios de um estudante de 12 anos de idade com altas habilidades nas áreas intelectual e acadêmica durante sua trajetória escolar, desde a Educação Infantil até o $8^{\circ}$ ano do Ensino Fundamental II, inclusive sobre o período de ensino remoto necessário no ano de 2020. Considerou-se ainda, sua identificação tardia e os desafios enfrentados nos colégios em que estudou. Concluiu-se que a literatura, segundo autores como Renzulli, Virgolim, Sabatella e Delou entre outros, apresenta em suas pesquisas que poucos estudantes com tais habilidades têm sido devidamente identificados nas escolas públicas e privadas, afinal, a maioria dos profissionais da educação não reconhecem as necessidades especiais destes estudantes e não compreendem que a área das altas habilidades/superdotação, carregada de mitos e informações descontextualizadas, está inserida no contexto da Educação Especial.

Palavras-chave: EducaÇão Especial; Escolarização; Inclusão Educacional; AluNo SuPERDotado. 


\begin{abstract}
This is a case study on the need to identify and make curricular flexible for students who have characteristics of High Skills/Intelectual Giftedness. The student participating in this research resides and studies in a city located in the interior of the state of Paraná, and was identified as Bob, to preserve his identity. Analyzing the pedagogical work with the student and whether the teachers were prepared to identify students with Intelectual Giftedness in the classroom, became the problem of this research. The objective, therefore, was to present the challenges of a 12-year-old student with High Skills/Intelectual Giftedness in the intellectual and academic areas during his school trajectory, from Early Childhood Education to the 8th year of Elementary School II, including the period of remote education needed in the year 2020. It was also considered their late Intelectual Giftedness identification and the challenges faced in the schools where he studied. It was concluded that the literature, according to authors such as Renzulli, Virgolim, Sabatella and Delou, among others, shows in their research that few students with such skills have been properly identified in public and private schools, after all, most education professionals do not recognize the special needs of these students and do not understand that the area of High Skills/Intelectual Giftedness, loaded with myths and decontextualized information, is inserted in the context of Special Education.
\end{abstract}

Keywords: Special education. Schooling. Educational InClusion. Giftedness StuDENT.

RESUMEN Se discurre un estudio de caso sobre la necesidad de identificación y flexibilización curricular al estudiante que presenta características de alta habilidades/ superdotación (AH/SD). El estudiante participante de esta investigación vive y estudia en una ciudad ubicada en el interior del estado del Paraná, y fue identificado por Bob, para preservar su identidad. Analizar el pedagógico con el estudiante y se los profesores se encuentran preparados para identificaren estudiantes superdotados en el salón de clases, se quedó una problemática de esta investigación. Se tiene por objetivo, por lo tanto, presentar los desafíos de un estudiante de doce años de edad con altas habilidades en las áreas intelectual y académica durante su trayectoria escolar, desde la educación infantil hasta el octavo año de la Enseñanza Fundamental II, incluso sobre el periodo de enseñanza remota necesaria en el año 2020. Aun se consideró, su identificación tardía y los desafíos enfrentados en las escuelas en las cuales estudió. Se concluye que la literatura, segundo autores como Renzulli, Virgolim, Sabatella y Delou, entre otros, presenta en sus investigaciones que pocos estudiantes con tales habilidades han sido debidamente identificados en las escuelas públicas y privadas, al final, la mayoría de los profesionales de la educación no reconocen las necesidades especiales de estos estudiantes y no comprenden que en la área de las altas habilidades/superdotación, cargada de mitos e informaciones sacadas del contexto, está insertada en el contexto de la Educación Especial.

Palabras claves: Educación Especial; Escolarización; Inserción Educacional; Alumno Superdotado. 


\section{INTRODUÇÃo}

Desde a Idade Antiga, a inteligência é analisada e estudada, a princípio, por filósofos como Platão e Aristóteles, e, na Idade Média, por René Descartes e John Locke. Entre os séculos XIX e XX, os primeiros testes de inteligência foram formalizados por diferentes psicólogos como Francis Galton (EUA), Alfred Binet (FR), Charles Spearman (UK), Louis Thurstone (EUA) e Raymond Cattell (EUA). Lewis Terman (EUA) foi o primeiro estudioso a elaborar uma pesquisa significativa baseada em conhecimento empírico sobre as habilidades mentais superiores em crianças. "A inteligência, inicialmente concebida como um atributo da alma passou, paulatinamente, a incorporar conceitos como percepção e sensação e, além desses, memória, raciocínio, julgamento e pensamento" (VIRGOLIM, 2019, p. 239).

Em meados do século XX, Joy Paul Guilford (EUA), um psicólogo eminente, ao mencionar a falta de estudos sobre a criatividade "[...] reforçou a necessidade urgente de analisar esse construto, estabelecer suas relações com a inteligência e utilizá-la formalmente para o desenvolvimento das crianças na escola, a fim de promover o desenvolvimento de personalidades criativas" (VIRGOLIM, 2019, p. 64).

As ideias de Guilford abriram o diálogo sobre o papel de outras habilidades cognitivas na mente humana. Posteriormente ao estudo de Guilford, Ellis Paul Torrance (EUA) desenvolveu testes sobre a criatividade e a inteligência, mais tarde adaptados por Solange Wechsler no Brasil (VIRGOLIM, 2019).

Desde a década de 1970, estudiosos como Howard Gardner, Robert Sternberg e, especialmente, Joseph Renzulli têm se dedicado ao estudo da natureza das inteligências e o desenvolvimento das potencialidades humanas (VIRGOLIM, 2019). A partir destes estudos, deu-se início a uma análise mais detalhada sobre a inteligência e a criatividade de estudantes de todas as idades, o que incentivou políticas públicas e alcançou-se o termo atual - que sofreu ligeiras mudanças ao longo dos anos - Altas Habilidades/ Superdotação (PÉREZ, 2014). Inclusive, no ano de 2015, Suzana Pérez, presidente do Conselho Brasileiro para Superdotação (ConBraSD) afirmou no ofício $n^{\circ}$ 05/2015 que "[...] inadvertidamente está a ocorrer um equívoco no uso da nomenclatura, constando 'Altas Habilidades e Superdotação', ou ainda, 'Altas Habilidades ou Superdotação', sendo que o correto, deva ser 'Altas Habilidades/Superdotação' [...]”.

Dados estatísticos indicam que, aproximadamente, "[...] 3 a 5\% da população apresenta potencial acima da média estimada [...]” (BRASIL, 2006, p. 19). Segundo dados mais recentes do censo escolar de 2019, existem 48.133 estudantes com altas habilidades/ superdotação no país (INEP, 2019).

Para a produção desta pesquisa, com respeito aos procedimentos éticos, sob orientação da Resolução no 466/2012, item II - 23 e 24, o Termo de Consentimento Livre e Esclarecido (TCLE), que garante aos participantes da pesquisa o respeito aos seus direitos, e o Termo de Assentimento, foram devidamente assinados pelos pais e pelo próprio estudante. O TCLE garante à criança ou adolescente participante da pesquisa, os devidos esclarecimentos sobre a natureza do artigo, com o uso de termos acessíveis e linguagem não científica, para melhor compreensão de que o estudante e a família estariam participando da produção de um 
artigo científico, que poderia inclusive ser publicado em um periódico de grande alcance. $\mathrm{O}$ estudante foi então, identificado como Bob, à sua própria escolha, para que sua identidade fosse preservada. Analisou-se o relatório descritivo da avaliação psicoeducacional do estudante e realizou-se entrevista não estruturada com a mãe do estudante, de forma presencial, na qual foi introduzido "[...] uma pergunta suficientemente aberta para deixar que o entrevistado escolha o que irá falar, mas com certa direção, dentro de um campo semântico" (MANZINI, 2020, p. 97), que considerou o processo de suspeita e descoberta das AH/SD e encaminhada a dois juízes com experiência na área, a fim de obtermos informações consistentes ao objetivo dessa pesquisa. Para a entrevista foram observados os devidos cuidados necessários solicitados pela OPAS (2020) em função da pandemia do COVID-19.

Portanto, com destaque para a descrição de Delou "[...] alunos com altas habilidades/ superdotação podem ser reconhecidos pelo alto desempenho escolar, mas não são incluídos nas práticas pedagógicas escolares de alto nível" (2007, p. 27), a presente pesquisa, por meio de análise de dados qualitativos sobre os desafios enfrentados por um estudante com AH/SD em sua vida escolar, se impulsiona pela problemática das seguintes questões: como ocorreu o trabalho pedagógico com um estudante com altas habilidades/superdotação nas três escolas privadas e na escola pública em que Bob estudou? Os professores se encontravam preparados para identificar estudantes com $\mathrm{AH} / \mathrm{SD}$ em sala de aula e trabalhar com as suas especificidades?

\section{FundamentaÇão Teórica}

Segundo Virgolim (2019, p. 69), Piaget "[...] procurou explicar o desenvolvimento intelectual por meio de mudanças no desenvolvimento do funcionamento cognitivo", enquanto Vygotsky "[...] defendia a ideia de que a aquisição do conhecimento [...] é um processo que se dá pela experiência e que é mediado pela vivência da criança na sociedade" (VIRGOLIM, 2019, p. 72). Contudo, sabe-se que ambos os estudos são importantes, pois em relação aos superdotados, "[...] sua estrutura cerebral dispõe de maior número de células gliais e conexões sinápticas, resultado da interação favorável entre padrões genéticos e oportunidades proporcionadas pelo meio" (SABATELLA, 2008, p. 29).

De acordo com Virgolim (2019), Gardner (1995) propôs em seus estudos sobre a inteligência humana, oito diferentes tipos de inteligências: a linguística, que é a capacidade oral e escrita; a lógico-matemática aborda a capacidade de lidar com números; a espacial, pela compreensão de informações gráficas e mapas; a interpessoal, que é a habilidade de liderança e sensibilidade às necessidades alheias; a intrapessoal, que se dá pelo conhecimento de si próprio; a corporal-cinestésica, que é a capacidade do corpo ou parte dele em desempenhar uma tarefa ou modelar algo; a musical, que se refere à sensibilidade a ritmos e sons; e a naturalista, que está ligada aos conhecimentos da natureza. Segundo a teoria de Gardner

[...] as habilidades e inteligências se combinam para que o indivíduo possa desempenhar os diversos papéis exigidos na sua cultura ou para desenvolver produtos culturais. Normalmente uma criança não apresenta apenas um tipo de inteligência; ela pode combinar muitas delas para desempenhar um determinado papel ou desenvolver algum produto (VIRGOLIM, 2007, p. 54). 
Já Sternberg (1983), segundo menciona Virgolim (2019, p. 79) “[...] propõe uma teoria triárquica da inteligência, a qual sinaliza que a inteligência não é uma construção fixa e unitária; vai além da noção tradicional de capacidade acadêmica".

Virgolim (2019) explica que Sternberg, em sua teoria, destaca três tipos de inteligência: a analítica, vista no estudante que aprende com facilidade, tira boas notas e analisa pensamentos e teorias; a criativa, por causa da imaginação e habilidade em gerar ideias; e a inteligência prática, pela facilidade em desempenhar atividades e se adaptar ao ambiente.

Entretanto, Virgolim (2019) destaca que apesar das teorias de Gardner (1995) e Sternberg (1983) serem de grande valia para o contexto escolar, por destacarem que cada indivíduo aprende de uma forma diferente e apresenta habilidades diversas que devem ser identificadas e estimuladas de forma adequada. Renzulli (1986), por sua vez, foi o pesquisador que criou conceitos e formas detalhadas de se trabalhar as altas habilidade/superdotação nas escolas. Segundo Virgolim (2019, p. 81) a teoria de Renzulli “[...] está diretamente relacionada ao entendimento, à identificação, ao enriquecimento escolar e à educação de crianças e jovens superdotados e tem correlação próxima com as teorias de Gardner e Sternberg”.

Renzulli (2014) descreveu sua concepção de superdotação por meio de uma teoria que consiste na intersecção de três anéis, a qual nomeou de Teoria dos Três Anéis (figura 1), em que o primeiro anel representa a habilidade acima da média, que é a maior facilidade de aprendizado do indivíduo perante seus pares; o segundo anel trata da criatividade que ocorre pela capacidade imaginativa e criação de estratégias; e o último anel representa o envolvimento com a tarefa, que se refere à motivação em relação a assuntos de interesse do indivíduo. E é na intersecção destes três anéis que se encontra a superdotação.

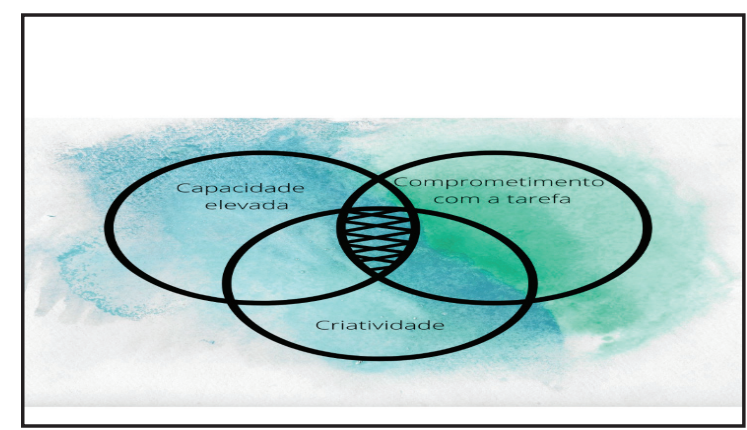

Figura 1 - Representação gráfica da Teoria dos Três Anéis

Fonte: Diagrama elaborado pelos autores e adaptado de Renzulli e Reis (1997, p. 287)

As concepções de Renzulli (2014) assinalam que o comportamento do estudante que é determinado por habilidade acima da média pode atingir o mais alto nível na área do desenvolvimento humano por apresentar fatores gerais, quando o processamento das informações permite respostas adequadas e assertivas a uma situação inesperada; e fatores específicos, pela aptidão que o estudante apresenta em adquirir conhecimentos técnicos e/ ou tarefas específicas.

O compromisso com a tarefa, segundo Renzulli (2014) é manifestado pela motivação do sujeito na realização de atividades de seu interesse particular, que persistirá na busca 
por resultados com dedicação e autoconfiança. Com isto, evidencia-se o aspecto intrínseco, inerente ao ser humano, que pode ocasionar-lhe crença sobre sua competência e autonomia; e extrínseco, quando o sujeito é encorajado por razões de recompensas.

Ser criativo é uma característica de pensamento divergente do superdotado (RENZULLI, 2014) que compreende o pensamento original e habilidades que permitem ignorar procedimentos predeterminados. É na convergência dos três traços, portanto, que se designa este comportamento que será exposto em determinadas circunstâncias. É na escola, por sua vez, que a variedade de oportunidades educacionais, de apoio, de estímulo, do uso de recursos diversos poderá incentivar estudantes com $\mathrm{AH} / \mathrm{SD}$ a desenvolverem e a aprimorarem suas habilidades.

Segundo o teórico, a partir da concepção da Teoria dos Três Anéis, “[...] os indivíduos capazes de desenvolver comportamento superdotado são aqueles que possuem ou são capazes de desenvolver esse conjunto de traços e aplicá-los a qualquer área potencialmente valiosa do desempenho humano" (RENZULLI, 2014, p. 544).

Com a ideia de especificar a superdotação, Renzulli (2004) propôs a diferença entre dois tipos: a escolar ou acadêmica, que possibilita maior apropriação dos conhecimentos científicos, sobre a qual o autor enfatiza que "[...] deveríamos fazer tudo, dentro de nossas possibilidades, para fazer as modificações apropriadas para os alunos que têm capacidade de vencer o material do currículo regular com ritmo e níveis de compreensão maiores que os dos seus pares" (RENZULLI, 2004, p. 82). E o segundo tipo, que é a superdotação produtivo-criativa, na qual se destaca a criatividade e a facilidade imaginativa de criar estratégias para a resolução de problemas e/ou novas criações e produtos. De forma adequada, "[...] as situações de aprendizagem [...] enfatizam o uso e a aplicação do conhecimento e dos processos de pensamento de uma forma integrada, indutiva e orientada para um problema real" (RENZULLI, 2004, p. 83).

Renzulli (2014) criou, ainda, modelos de aprendizagem, como o Modelo Triádico de Enriquecimento que traz três tipos de atividades que podem ser realizadas com todos os estudantes no ensino comum e não somente com os superdotados em que

[...] o enriquecimento do tipo I foi elaborado para expor os alunos a uma ampla variedade de disciplinas, temas, profissões, hobbies, pessoas, locais e eventos que normalmente não estão incluídos no currículo regular. [...] O enriquecimento do tipo II foi principalmente elaborado para estimular novos interesses que levam ao seguimento do tipo II ou III pelos alunos que ficam motivados pelas experiências do tipo I (p. 545-546). E já o enriquecimento do tipo III, fica disponibilizado aos que [...] ficaram interessados em procurar uma área de interesse determinada e querem comprometer o tempo e os esforços necessários para a aquisição de conteúdo avançado e o treinamento de processos nos quais eles assumem um papel de pesquisador de primeira categoria (p. 546).

A partir deste padrão, Renzulli (2014) criou o Modelo de Enriquecimento para toda a escola (Schoolwide Enrichment Model-SEM), que vai além do Modelo Triádico, cujo principal objetivo é "[...] introduzir no currículo regular um currículo expandido de oportunidades de atendimento, recursos e apoio para os professores que misture mais enriquecimento e uma aprendizagem mais investigativa na experiência de toda a escola" (RENZULLI, 
2014, p. 541) para oportunizar o desenvolvimento de criatividades e a demonstração de talentos de estudantes superdotados, para que se tornem parceiros da escola e responsáveis pelas suas aprendizagens com paixão e prazer em aprender.

Em consonância com a ideia de Renzulli (2014) sobre proporcionar um ensino diferenciado a todos os estudantes das salas comuns, a Secretaria de Estado da Educação e do Esporte (SEED/PR) complementa que, para o efetivo ensino é preciso

[...] otimizar a provisão de serviços e recursos para atender a todos os alunos, independentemente de apresentarem diferenças significativas, reconhecendo que a escola tem como fim desenvolver as capacidades acadêmicas, cognitivas, afetivo-emocionais e sociais que potencializem o desenvolvimento pessoal de cada um deles (PARANÁ, 2006, p. 56).

Segundo Sabatella (2008, p.21) “[...] é difícil avaliar a inteligência e a determinação de um aluno até que lhe seja ofertado um ambiente escolar favorável, no qual possa ser desafiado adequadamente". Com esse propósito, Renzulli (2014) criou o Pool de Talentos, que consiste nas anotações do professor para coletar, classificar, revisar e analisar todos os dados obtidos por meio das atividades investigativas e enriquecedoras registradas em um Portfólio Total do Talento (PTT) individual, com mecanismos formais e informais que possibilitem a identificação e avaliação das informações sobre os interesses de cada estudante, de maneira que possam perceber características de AH/SD nestes estudantes, e negociar opções de ajustes curriculares a fim de que não haja repetição de conteúdo para estes que se apresentam acima da média, garantindo-lhes, desta forma, atividades adequadas e desafiadoras, aceleração e/ou indicação para o atendimento por profissionais especialistas em Salas de Recursos Multifuncionais - Altas Habilidades/ Superdotação (SRM-AH/SD). Afinal, "[...] a capacidade e talento humano se desenvolvem, e se expressam em produção superior, desde que o potencial seja identificado, estimulado, acompanhado e orientado" (GUENTHER, 2006, p. 31).

Com base no Modelo de Enriquecimento de Renzulli, para toda a escola, no ano de 2007, o Ministério da Educação (MEC) elaborou políticas de ensino e aprendizagem que estão descritas em apostilas gratuitas no site do MEC. Com isso, adotou-se cinco áreas distintas para os estudantes que apresentam $\mathrm{AH} / \mathrm{SD}$

Estudantes com Altas Habilidades/Superdotação são aqueles que demonstram potencial elevado em qualquer uma das seguintes áreas, isoladas ou combinadas: intelectual, acadêmica, liderança, psicomotricidade e artes. Também apresentam elevada criatividade, grande envolvimento na aprendizagem e realização de tarefas em áreas de seu interesse (BRASIL, 2008, p. 15).

As áreas citadas pelo MEC, de acordo com Sabatella (2008), apresentam as seguintes características: a área intelectual, que só pode ser medida por meio de testes psicométricos, apresenta um estudante com Quociente de Inteligência (QI) maior ou igual a 130, e envolve rapidez de pensamento, compreensão, capacidade de abstração e memória elevada, 
curiosidade e grande facilidade de abstração; a área acadêmica compreende motivação por áreas específicas de interesse, atenção, concentração e alto desempenho escolar; na liderança encontra-se estudantes com poder de persuasão e influência no grupo e grande sensibilidade interpessoal com capacidade de resolver situações sociais complicadas; a área da psicomotricidade refere-se ao alto desempenho em atividades físicas, esportes, força, resistência, agilidade de movimentos e velocidades, além de excelente controle das coordenações motoras grossa e fina; na área artística, nota-se estudantes com excepcional talento para artes plásticas, cênicas, literárias ou musicais. E cada estudante com AH/SD pode apresentar uma ou mais áreas de habilidade.

Os indivíduos com altas habilidades/superdotação, portanto, não são representados por um grupo homogêneo que varia

[...] tanto em suas habilidades cognitivas, como em termos de atributos de personalidade e nível de desempenho. Assim, enquanto alguns podem apresentar uma competência elevada em uma grande diversidade de áreas, outros podem mostrar-se excepcionalmente competentes em apenas uma área (ALENCAR, 2007, p. 19).

Sabatella (2008) salienta que há traços típicos, citados também por outros autores, que podem auxiliar na identificação de estudantes com $\mathrm{AH} / \mathrm{SD}$, como: criatividade; curiosidade; imaginação; criticidade consigo mesmo e com os demais; persistência; facilidade em propor ideias, mostrar opiniões e argumentar; intuição; alta capacidade de memorização; capricho e minuciosidade; senso de humor elevado; sensibilidade em relação a injustiças; perceptividade; pensamento divergente; preferência por conversar com adultos; gosto por aprender, mas não por atividades repetitivas ou pela escola; originalidade de ideias; perfeccionismo; facilidade de abstração e contextualização de ideias; dificuldade em aceitar informações e/ou respostas superficiais; originalidade na resolução de problemas; independência; flexibilidade de pensamento; autossuficiência; vocabulário diversificado e avançado; auto iniciativa; habilidade de comunicação; autenticidade; excelente raciocínio; capacidade elevada de observação; ponderação; facilidade de decisão; atenção e concentração prolongada em assuntos de seu interesse; alto nível de pensamento e produção intelectual; desenvolvimento moral avançado; velocidade no processamento de informações; inquietação diante de possíveis problemas; preocupação; ansiedade; inadequação social; dentre vários outros traços.

Vale ressaltar que tais características, assim como as áreas de habilidade não estão todos presentes nos estudantes superdotados, pois eles "[...] diferem amplamente entre si em relação aos interesses, estilos de aprendizagem, níveis de motivação e de autoconceito, características de personalidade e, principalmente, por suas necessidades educacionais" (VIRGOLIM, 2019, p. 108).

Virgolim (2019, p. 195) destaca ainda, a questão do assincronismo mencionado por Silverman (1993) que

[...] defende que essas crianças e esses jovens apresentam um desenvolvimento assincrônico, palavra cunhada por ela para se referir às habilidades cognitivas avançadas que se combinam com a grande intensidade com que essas pessoas 
vivenciam o mundo, criando experiências internas e um grau de consciência qualitativamente diferentes de seus pares. Devido a essa grande sensibilidade, a criança ou o jovem oscila entre momentos de grande avanço emocional e outros de imaturidade.

Segundo Virgolim (2019, p. 197), Silverman compreende a assincronia como “[...] função de um desenvolvimento que se dá de forma desigual, fora de sintonia com pares de mesma idade cronológica, o que é responsável pela vulnerabilidade social e emocional da pessoa superdotada". Isto posto, Barreto (2014) afirma que "[...] da mesma forma como apresentam capacidades diferenciadas e talentos especiais, os superdotados experimentam o mundo ao seu redor de maneira incomum" (p.189).

Desta forma, nota-se que perceber o estudante superdotado em sala de aula é importante não somente em relação ao seu sucesso escolar, mas também para evitar que o estudante desenvolva problemas emocionais, pois "[...] mais do que nunca, precisamos validar seus sentimentos e ajudá-lo a melhor direcionar a expressão de suas emoções" (VIRGOLIM, 2019, p. 204).

[...] estes alunos também têm necessidades educacionais especiais e, por este motivo, precisam ser identificados e atendidos de modo especializado nas escolas. Este é o lugar destes alunos, cidadãos como os demais e que têm direito à educação de qualidade e de alto nível (DELOU, 2007, p. 39).

A legislação brasileira regulamenta que "[...] a educação especial se destina às pessoas com necessidades especiais no campo da aprendizagem, originadas quer de deficiência física, sensorial, mental ou múltipla, quer de características como altas habilidades, superdotação ou talentos" (BRASIL, 2001, p. 55).

Assim, para que a percepção da existência destes estudantes se efetive, os professores, de posse das observações realizadas, tanto em relação às características apresentadas por Sabatella (2008), como pelas anotações oferecidas pelo Pool de Talentos Renzulli (2014) devem selecionar estes estudantes e repensar sobre seu trabalho pedagógico, pois “[...] uma vez documentada a área em que o aluno já domina, o professor indica as atividades que podem ser eliminadas do currículo ou aceleradas para se adaptar ao ritmo próprio do aluno" (VIRGOLIM, 2007, p. 62-63). E "[...] cabe aos professores das matérias em que o aluno demonstra maior habilidade e/ou maior interesse oferecer conteúdos para serem estudados de forma independente ou semi-independente" (GAMA, 2007, p. 67).

Tais adaptações devem constar em um plano de trabalho individualizado que "[...] se baseia no pressuposto de que cada necessidade é única e particular, e como tal, o atendimento aos talentos e habilidades identificados em cada aluno exigirá um direcionamento individualizado" (BRASIL, 2006, p. 106).

Entretanto, é importante destacar que "[...] os professores graduados em cursos universitários de qualquer área raramente tiveram conteúdos relacionados às AH/SD." "[...] afirmação praticamente unânime dos pedagogos, psicólogos e educadores de todos os cantos do país" (PÉREZ, 2014, p. 634).

Neves-Pereira $(2007$, p. 24) afirma que "[...] tanto o setor público como o setor privado do ensino não assumiram, ainda, um compromisso genuíno com a promoção da cria- 
tividade na escola", e ainda, os cursos de Educação Especial, em sua maioria, se dedicam às deficiências mais comuns, como as deficiências física, intelectual, auditiva e visual. Já a área da superdotação

[...] por se tratar de um tema ainda não aprofundado na Educação Especial, geralmente não associado a ela, e povoado de mitos e crenças populares, as AH/ SD não são incluídas nos cursos de formação inicial nem continuada; [...] e os estudantes que apresentam esse comportamento não são identificados, acreditando-se que eles não existem (PÉREZ, 2014, p. 631).

Segundo Moreira (2009, p. 268), as universidades devem oferecer uma "[...] formação que viva a inclusão e ultrapasse a linearidade e a simplificação curricular de que basta uma disciplina sobre a área da NEE para formar professores capacitados a atuarem com o alunado que apresenta necessidades mais específicas".

Desta forma, a não identificação dos estudantes com AH/SD nas escolas pode permitir a exclusão escolar se não forem reconhecidas suas habilidades. Pois " [...] de geração em geração, vamos perdendo matéria-prima de primeira mão, os frutos de novas ideias e soluções para problemas diversos que habitam a mente dos homens, mas não encontram a via de saída, por falta de informação, treino e oportunidade" (FLEITH, NEVES-PEREIRA; VIRGOLIM, 2009, p. 11).

\section{AS DIFICULDADES ENFRENTADAS POR BOB DURANTE SUA VIDA ESCOLAR: RELATOS}

Segundo relatos da mãe, Bob sempre foi uma criança muito inteligente e especial, com interesses incomuns e desenvolvimento intelectual acima do esperado. Ao completar quatro anos de idade, já lia e escrevia palavras soltas e até pequenas frases. Poucos meses depois, já lia sozinho seus livros de estórias, os quais interpretava com facilidade.

Bob iniciou na escola aos dois anos de idade porque a família, que não entendia nada sobre AH/SD na época, achava que o convívio com adultos estava apressando sua maturidade. No Jardim II, aos quatro anos, a família foi chamada à escola para uma séria conversa com a diretora e a coordenadora da Educação Infantil. Segundo a diretora, Bob só queria brincar no parque e se recusava a realizar as atividades. Por ser mais novo que os demais estudantes, pois aniversariava no final de dezembro, apresentava imaturidade e deveria voltar para o Jardim I a fim de se adequar melhor. A coordenadora, a pedido da mãe, mostrou o caderno do "melhor aluno da turma" e disse que as crianças treinavam com afinco as letras do alfabeto, o que expôs claramente a falta de interesse do estudante que já lia e escrevia com facilidade, porém, a escola não havia percebido.

Após várias reuniões entre a equipe e a mãe de Bob, o estudante passou a fazer desenhos aleatórios em seu caderno extra ou ler algum livro que carregava consigo, nos momentos em que ficava ocioso. Passou a ser atendido, em ocasiões apropriadas, na sala da mentora do colégio que já era idosa, mas ainda frequentava o espaço. Ela apresentava pequenos textos para que Bob fizesse a leitura em voz alta, explicasse e debatesse com ela 
sobre a estória e depois, quando possível, eles conversavam, faziam outras leituras, escritas e desenhos. O estudante passou a amar aquele colégio e sua tutora, por quem até hoje se lembra com imenso carinho. Essas aulas diferenciadas persistiram, conforme a necessidade em cada ano, até que Bob foi transferido de colégio no ano de 2014, quando a família se mudou de cidade.

No novo colégio a mãe conversou com a professora e a coordenadora para que Bob pudesse continuar com as leituras e desenhos em seu tempo ocioso, enquanto os demais concluíam as atividades, sendo prontamente atendida. No entanto, Bob sofreu bullying por responder às perguntas dos professores mais rapidamente do que seu colega que era considerado o mais inteligente da turma até então. Após grande insistência da mãe, Bob acabou contando que um amiguinho não gostava dele e lhe disse que devia parar de responder as perguntas da professora, caso contrário bateria nele.

A mãe foi até a escola e conversou com a coordenadora, que defendeu o tal estudante e disse que Bob deveria estar apenas com dificuldades de adaptação devido à mudança, gerando conflitos imaginários. Tal processo acabou sendo resolvido por meio de conversas e conselhos da própria mãe com o filho, que por fim, aprendeu a se defender do colega.

$\mathrm{O}$ ano seguinte foi um grande problema, pois a professora não permitia que Bob desenhasse e lesse nos intervalos das atividades, o que lhe causou um grande desinteresse pela escola, além de indisciplina, pois ao ficar ocioso, conversava. No início do segundo semestre, a professora solicitou um trabalho aos estudantes incompatível com a idade e capacidade da maioria. Bob realizou o trabalho com muito capricho e tão logo entregou à professora, foi avisado de que o trabalho seria cancelado, pois vários pais haviam reclamado com a coordenação em relação à dificuldade apresentada. Bob foi o único a executar a atividade trabalhosa, a professora recusou seu trabalho e o estudante voltou para casa triste com o trabalho nas mãos.

Mais uma vez, lá estava a mãe na coordenação a reclamar que a professora recebesse o trabalho e lhe atribuísse nota. A mãe mencionou que concordava com a dificuldade da tarefa, mas o filho havia realizado com precisão e merecia a nota devida, reclamou da forma com que a professora tratou o filho e como ficou triste por não ter recebido os "parabéns" da professora. A coordenadora concordou com a mãe, mas simplesmente não tocou mais no assunto.

Essa mesma professora sempre proporcionava trabalhos em grupos, ou ao menos em duplas, que eram constantes por meio de rodízios, o que nada agradava ao Bob. O estudante sempre se frustrava com a "enrolação" e "ideias ruins" dos amigos, como ele mesmo dizia.

Um dia, a professora o colocou em dupla com uma estudante que frequentemente era levada até a coordenação por não realizar as atividades em sala, segundo relatos de Bob e seus colegas de turma. Ambos tinham em suas mãos um questionário a responder, que segundo a professora deveria apresentar respostas iguais, após debate da dupla. De acordo com relato de Bob à mãe, a aluna não fez nada no trabalho, só ficou pintando a capa enquanto Bob, desesperado por ver o tempo passar, resolveu as questões sozinho e pediu à estudante que copiasse as respostas, sem sucesso. Então, entregou à professora, que lhe disse que ele havia descumprido a regra e não se importou com a colega, foi egoísta e maldoso e que esse não era um comportamento adequado. $\mathrm{O}$ fez apagar todas as suas respostas e entregar o trabalho em branco. 
Já era o momento de saída, e a mãe encontrou o filho chorando ao buscá-lo. De posse dos fatos foi diretamente até a professora na sala da coordenação para conversarem. A conversa foi longa, muitos ajustes foram realizados, pedidos de desculpas, mas a mãe permaneceu insatisfeita e preocupada, pois gostaria de transferir o filho para outra escola, porém, ele pediu que esperassem um pouco mais.

No ano seguinte, não houve problemas com a professora da sala, Bob voltou a utilizar seus livros e caderno de desenho nos momentos vagos e tudo correu bem. Entretanto, foi implementada a aula de xadrez que o estudante aguardava ansiosamente, mas a professora sempre entrava em discussão com Bob por divergências em relação às regras do jogo, o que com o tempo, tornou as aulas tão aguardadas em um grande pesadelo.

A professora fez reclamações de que Bob "queria saber mais que ela", foram estas as palavras relatadas à mãe, porém, a mãe levou as tais regras à coordenação, por haver pesquisado sobre as argumentações do filho, e solicitou que as analisassem e pesquisassem também em outras fontes. Mais uma vez, imperou o silêncio e não houve resposta.

No $5^{\circ}$ ano, o colégio proporcionava aos estudantes a diferenciação de professores por disciplinas. Bob gostou da nova dinâmica, tinha professores que considerava muito bons em relação à didática e ao conteúdo e o tempo ocioso era menor. No entanto, a escola exigia a cópia das questões nos cadernos com "respostas completas". Essa metodologia consistia em praticamente copiar toda a questão novamente para então respondê-la, o que para Bob era uma imensa tortura.

A mãe foi até a escola sugerir que se alterasse tal metodologia, pois considerava cansativa e desnecessária, porém, não foi atendida e Bob passou por mais um ano difícil. Foi então que Bob desenvolveu enxaqueca, aos nove anos de idade, e começou a pedir para faltar constantemente às aulas. E em meio ao tratamento com neuropediatra e homeopata, Bob permaneceu no mesmo colégio, por sua vontade e a contragosto dos pais, e iniciou o $6^{\circ}$ ano com uma nova coordenação, com a qual a mãe, unida a outras mães, apresentaram descontentamento e finalmente as respostas completas foram retiradas. Entretanto, havia aulas extras, professores que não compreendiam as necessidades especiais do estudante, $\mathrm{e}$ excesso de regras para com ele, como por exemplo, não poder ler e/ou adiantar as tarefas de casa. Tudo isso, aumentava a cada semana as crises de enxaqueca de Bob, que não apresentava mais interesse algum pela escola. Seu prazer era aprender em casa, com leituras e vídeos e a escola era vista mais do que nunca como algo desnecessário e desanimador.

O professor de Filosofia solicitava trabalhos decorativos e avaliações pouco reflexivas com vários exercícios de "complete", o que levava Bob a uma grande frustração, pois não conseguia compreender o objetivo da disciplina e detestava ter que decorar parágrafos inteiros do livro didático. Apesar de sua grande capacidade de memorização, Bob gosta de analisar e debater os assuntos estudados, e não via sentido em estudar a disciplina dessa forma. Nesse ano, o estudante apresentou muitas faltas e a família decidiu que era definitivamente o momento de procurar uma nova escola.

No novo colégio, Bob se adaptou rapidamente e se sentiu novamente motivado. Contudo, assim como no colégio anterior, os exageros nas tarefas e os resumos excessivos de conteúdos surgiram, e toda a motivação de Bob desapareceu, ao mesmo tempo que as crises de enxaqueca aumentaram novamente. 
A família conversou seriamente com o neuropediatra que solicitou uma ressonância para analisar mais detalhadamente as possíveis causas da enxaqueca. E após os medicamentos profiláticos (controlados) serem a única saída, sob orientação médica, a família transferiu o filho, que sempre estudou na rede privada de ensino, para o colégio público, local de trabalho da mãe, com o intuito de que pudesse ser medicado rapidamente, o que poderia diminuir o tempo das crises, que duravam até três dias consecutivos.

E foi então que Bob iniciou o $2^{\circ}$ trimestre do $7^{\circ}$ ano na rede pública de educação no ano de 2019. O estudante se adaptou muito bem ao novo colégio e gostou dos professores, que eram, segundo Bob, os melhores que já teve, com algumas poucas exceções. O foco principal que era a enxaqueca, com a medicação rápida da mãe, apresentou grande melhora. Porém, a maioria dos professores do colégio também não permitia que Bob adiantasse as tarefas de casa ou levasse livros para a sala de aula, nem mesmo os livros didáticos, para que preenchesse o tempo ocioso após concluir as atividades propostas em sala de aula. Algumas explicações de conteúdos que o estudante já havia assimilado, o deixava entediado, pois não apresentava motivação ou interesse em ouvi-las novamente.

No quadro de funcionários havia uma excelente professora de Geografia no $7^{\circ}$ ano, porém, ela aposentou no início do $3^{\circ}$ trimestre, sendo substituída por uma que não aceitava que os estudantes fizessem perguntas, o que gerou intensa frustração ao estudante. Cada aula foi um sofrimento até que uns estudantes inquietos e brincalhões começaram a fazer piadas durante as aulas, tornando-as mais "interessantes" segundo Bob, que estudava Geografia em casa sozinho, pelo livro didático.

No ano seguinte, 2020, apesar de excelentes professores em sua turma, o estudante não gostava das aulas de inglês, língua em que já é fluente. Segundo Bob e suas posteriores pesquisas para fins de certificação, algumas pronúncias da professora não eram corretas, citava até mesmo traduções incorretas e o estudante ficava desesperado por não poder corrigir a professora e alertar os colegas.

Contudo, logo chegou à pandemia do COVID-19 e com ela o isolamento, que permanece até a presente data desta pesquisa, o que deu fim à agonia do estudante. $\mathrm{O}$ único problema que perdurou durante as aulas remotas foi a metodologia e a falta de empatia da professora de Matemática, disciplina que Bob sempre gostou, mas acabou perdendo o interesse durante esse ano, inclusive deixou de lado o desejo em se formar em Engenharia Civil, devido à necessidade do uso da Matemática.

Segundo Bob relatou à mãe, a professora apresenta conteúdo e didática para explicar as temáticas, porém, é muito tradicional e não aceita as formas diferentes que o estudante utiliza para realizar as atividades, mesmo corretas. Bob já é capaz de discernir sobre os conteúdos e didática adequados ao seu aprendizado, e a pedagoga mencionou que a professora não aceita opiniões contrárias à sua metodologia.

No início do ano, com a suspeita de que o filho apresentava características de AH/SD, a mãe o encaminhou para uma avaliação psicoeducacional em um instituto de Psicologia privado, por acreditar ter chegado a hora, já que estudava sobre o assunto desde que soube de tal possibilidade, no ano de 2015.

De posse da avaliação psicoeducacional de Bob, a mãe comunicou os resultados à pedagoga do colégio, que já nas primeiras semanas de aula entrou em conflito com a pro- 
fessora de Matemática, por ter exigido de Bob que refizesse um trabalho em que havia acertado todas as questões, porém, realizou os cálculos de forma diferenciada que, segundo a professora, não seria possível o estudante ter chegado aos resultados apresentados, sem ter "colado" de algum colega.

O conflito se deu porque a pedagoga comentou sobre as AH/SD do estudante e explicou que a professora deveria aceitar a forma criativa com que Bob resolveu as questões, afinal, estavam corretas. Contudo, a professora não aceitou a sugestão da pedagoga, a desafiou e disse que levaria o assunto à direção. Em seguida, ocorreu a pandemia e a questão não foi concluída.

Durante as aulas remotas, a professora continuava a solicitar os exercícios "completos", cópias de páginas inteiras do livro e outras atividades nas quais, para Bob, não havia sentido algum. Era sempre descortês com o estudante e com a mãe nos atendimentos pela plataforma de atividades ou por e-mail.

Ao final do $1^{\circ}$ trimestre, a professora de matemática descontou nota do estudante de maneira infundada, e até mesmo com a intervenção de toda a equipe gestora do colégio, não assumiu sua inadequação. Por fim, após conversar com o filho a respeito das discussões, a mãe decidiu dar por encerrado o assunto e enviou um e-mail à professora para que tais perseguições não voltassem a ocorrer, o que aparentemente surtiu efeito.

Durante as aulas remotas, Bob não teve paciência para assistir as aulas televisivas, que, segundo o estudante, são insatisfatórias. Assim, lê e estuda pelos livros didáticos e realiza as atividades de todas as disciplinas sozinho, com excelente facilidade de interpretação e abstração de informações.

A pandemia Covid-19 tem proporcionado um momento feliz para Bob em relação à escola, pois ele estuda à sua maneira, ao seu tempo e comenta com os pais os conteúdos que julga mais interessantes. Pode questionar, comentar e criticar ideias com pessoas que $o$ compreendem e atendem às suas necessidades acadêmicas, pois na escola, muitas vezes, se sente constrangido em demonstrar todo o seu conhecimento, o que o leva a comentar tais assuntos somente em casa. E essa frustração de ter de esperar para comentar, não ocorre durante o período de isolamento, o que lhe proporciona grande satisfação.

Por gostar muito das disciplinas de História e Geopolítica, as conversas diárias com a mãe, que é Socióloga, e está em trabalho remoto, possibilita a Bob adentrar aos assuntos que deseja quando sente vontade, o que o deixa satisfeito e feliz. Sua paz interior é tão grande, que segundo a mãe, o filho teve somente uma crise de enxaqueca desde o início do isolamento até o último contato em entrevista, o que há anos ocorria semanalmente.

\section{A aValiação pSicoeducacional}

No início de 2020, Bob foi encaminhado para avaliação psicoeducacional com uma Psicopedagoga e uma Psicóloga, que analisaram todos os campos de seu aprendizado com testes formais e informais para se detectar AH/SD em estudantes da idade de Bob.

A respeito dos resultados da avaliação encontrou-se: aspecto criativo/imaginativo: é capaz de perceber e analisar os acontecimentos e fatos sob diversos ângulos. Quando se depara com uma situação problema, consegue levantar variadas opções, com características únicas e criativas, escapando do senso comum, buscando soluções inusitadas; aspecto 
social/afetivo: consegue se incluir no contexto que está inserido, percebe o outro de forma empática, conseguindo se colocar no lugar deste, inferindo seus sentimentos. De forma geral, está entre os estudantes menos motivados no que se refere à prática escolar; aspecto intelectual/cognitivo: na análise do Quociente de Inteligência (QI) pode-se verificar que a habilidade cognitiva geral supera aproximadamente $99 \%$ das crianças da sua idade QIT $(\mathrm{QI}$ Total $)=136$. Demonstrou melhor desempenho nos subtestes da área de Velocidade de Processamento. É capaz de refletir e emitir sua opinião a partir de uma situação problema envolvendo juízo moral com caráter social; aspecto pedagógico: se interessa por História, principalmente sobre a $1^{\mathrm{a}}$ e $2^{\mathrm{a}}$ Guerra Mundial, de ' 1770 pra frente', contando trechos e episódios destas fases com riqueza de informação e com empolgação, verbalizando frases como 'o ser humano não aprende, ele vê o erro do passado e não aprende'. Quando solicitado que dissesse três palavras que expressassem quem ele é, afirmou: pesquisador, feliz e inteligente. Sua expressão por meio da linguagem oral está acima da média para adolescentes de sua faixa etária, expressa-se como um adulto. Ao ler um texto, leu 146 palavras por minuto (o esperado é 60 palavras/minuto) com fluência e entonação. Foi capaz de recontar os fatos na ordem que aconteceram com riqueza de dados e quando questionado respondeu adequadamente fornecendo informações complementares, demostrando atenção, memória imediata e compreensão de conteúdo.

As profissionais concluíram que Bob evidencia habilidade intelectual acima do esperado para sua faixa etária e experiência, e apresenta os indicadores de comportamento de altas habilidades/superdotação, do tipo intelectual e acadêmico.

\section{RESULTADOS E DISCUSSÕES}

Ao comparar os relatos da mãe de Bob, vimos que a necessidade de identificar e trabalhar de forma diferenciada com estudantes que apresentam AH/SD em sala de aula é fundamental, pois ainda hoje, no ano de 2020, muitos estão ocultos e negligenciados em nosso sistema educacional. Eles são as grandes mentes da nossa sociedade e precisamos delas bem estimuladas, trabalhadas para o bem, a fim de proporcionar a todos, ideias, descobertas e soluções de muitos problemas. Segundo Savater (2000), a verdadeira educação não está apenas em ensinar a pensar, mas a aprender a analisar o que se pensa. Afinal,

Se entendermos os mitos que criamos para nos defender dos falsos perigos do afastamento da norma, talvez aprendamos a enxergar a beleza e a riqueza que a sábia natureza disseminou entre seus filhos e que faz deste nosso mundo o lugar mais maravilhoso, imperfeito e cheio de diferenças (SAVATER, 2000, p. 42).

No entanto, é preciso que haja conscientização de gestores e professores, que provavelmente conhecem mais mitos sobre as $\mathrm{AH} / \mathrm{SD}$ do que o real significado dessa alta habilidade diagnosticada em Bob, e o quanto tais estudantes precisam de atenção, dedicação e apreço destes profissionais, tanto quanto qualquer um dos demais estudantes com necessidades educacionais especiais. Porém, devido à desinformação da população em geral no Brasil, a 
[...] superdotação é ainda vista como um fenômeno raro e prova disso é o espanto e curiosidade diante de uma criança ou adolescente que tenha sido diagnosticado como superdotado. Observa-se que muitas são as ideias errôneas a seu respeito presentes no pensamento popular. Ignorância, preconceito e tradição mantêm viva uma série de ideias que interferem e dificultam uma educação que promova um melhor desenvolvimento do aluno com altas habilidades (ALENCAR, 2007, p. 15).

Salientamos que a superdotação é uma área da Educação Especial e Delou (2007, p. 33) destaca que "[...] a LDBEN não conceitua a expressão alunos com necessidades especiais, contudo faz menção aos alunos superdotados e prevê garantias para estes alunos no Capítulo V. Então, alunos superdotados são considerados alunos com necessidades educacionais especiais". Em conformidade com a necessidade de atendimento educacional diferenciado a estes estudantes, a Secretaria Estadual de Educação do Paraná, ressalta que

[...] a oferta de serviços e apoios especializados, em Educação Especial, destina-se a crianças, jovens e adultos com necessidades educacionais permanentes, em função de [...] superdotação ou altas habilidades que, devido às necessidades e motivações específicas, requeiram enriquecimento, aprofundamento curricular e aceleração na oferta de acesso aos conhecimentos (PARANÁ, 2006, p. 44-45).

Contudo, segundo Sabatella (2008, p. 111), “[...] no Brasil, a falta de capacitação dos educadores para identificar os estudantes com inteligência superior revela-se uma das maiores dificuldades para o desenvolvimento de ações dirigidas aos superdotados". Esta compreensão sobre as especificidades de estudantes com altas habilidades/superdotação poderia evitar frustrações ou desmotivações dos estudantes para a escolarização, como se percebe nos relatos da mãe e de Bob. Todavia, Sabatella (2008, p. 112), ressalta que

[...] a eficácia do professor ainda é limitada e discutível, a não ser que esteja associada a recursos que lhe tragam maior segurança, ou seja, feita com apoio de professores que já tenham treinamento para reconhecer os indicativos de altas habilidades e as características comportamentais do aluno superdotado.

Entretanto, diante de salas lotadas e pressão por números e índices que medem a qualidade do aprendizado em escolas públicas e privadas, a preocupação em olhar diferencialmente para aqueles que aprendem com facilidade e tiram boas notas, não tem sido preocupação de todos os profissionais das escolas relatadas.

\section{CONSIDERAÇões FINAIS}

Políticas públicas já existem, porém, é necessária maior formação continuada para os professores, informação às famílias e, principalmente, a compreensão de que estudantes com AH/SD necessitam de atenção e metodologias diferenciadas para o pleno desenvolvimento de suas habilidades dentro do contexto escolar. 
Ao evidenciar tantas críticas nas obras dos maiores autores sobre o assunto, analisar toda a capacidade intelectual e as características de superdotação mencionadas no relatório psicoeducacional de Bob e ao conhecer alguns percalços pelos quais o estudante passou durante sua vida escolar, fica-nos evidente a necessidade das escolas respeitarem as leis federais existentes no país e excluírem os paradigmas de estudantes público-alvo da Educação Especial para perceber e atender as especificidades destes estudantes.

$\mathrm{O}$ estudante passou por vários momentos confusos e desgastantes nos colégios que frequentou e ainda frequenta, dos quais poderiam ter sido evitados caso a legítima formação e comprometimento dos professores, para notar a existência dos estudantes com AH/ $\mathrm{SD}$ em suas salas de aulas, se efetivasse. Afinal, é primordial que o trabalho pedagógico direcionado aos estudantes superdotados seja diferenciado, e que a suplementação curricular necessária ocorra conforme as leis que regem o Brasil, e que trabalhos de pesquisadores na área de altas habilidades/superdotação sejam considerados, também como norteadores das práticas pedagógicas de profissionais da área da educação.

Portanto, por essas considerações, ainda há um longo caminho a percorrer para que os estudantes com altas habilidades/superdotação sejam vistos e devidamente atendidos. Famílias, professores, gestores e toda a comunidade escolar precisam apreender um pouco mais sobre as necessidades especiais dessas crianças e adolescentes, pois somente ao desmistificar ideias errôneas sobre o tema abordado neste trabalho, e reconhecendo seus talentos e habilidades, é que a inclusão dos estudantes com AH/SD poderá ser efetivada.

Compreender de forma adequada estes estudantes tão talentosos é, acima de tudo, um grande reconhecimento do bem que podem proporcionar para uma sociedade em geral e, portanto, responsabilidade de todos para que estes estudantes possam atingir o seu potencial mais alto de produtividade criativa.

\section{REFERÊNCIAS}

ALENCAR, E. M. L. S. Indivíduos com altas habilidades/superdotação: clarificando conceitos, desfazendo ideias errôneas. In: FLEITH, D. de S. (org). A construção de práticas educacionais para alunos com altas habilidades/superdotação: orientação a professores. Vol. 1. Brasília, MEC/SEESP, 2007.

BARRETO, C. T. Ele é superdotado, e daí?: relatos de uma mãe sobre a experiência real com a superdotação/ altas habilidades. São Paulo: All Print, 2014.

BRASIL. Lei n ${ }^{\mathbf{0}}$ 10172, de 09 de janeiro de 2001. Aprova o Plano Nacional de Educação e dá outras providências. Brasília, DF. 2001. Disponível em http://www.mec.gov.br. Acesso em: 21 out. 2020.

BRASIL. Ministério da Educação. Política Nacional de Educação Especial na Perspectiva da Educação Inclusiva. MEC/SEESP. Brasília, DF, 2008. Disponível em: http:// portal.mec.gov.br/arquivos/pdf/politicaeducespecial.pdf. Acesso em 29 out. 2020. 
BRASIL. Saberes e práticas da inclusão: desenvolvendo competências para o atendimento às necessidades educacionais especiais de alunos com altas habilidades/superdotação. 2 . ed. Brasília: SEESP/MEC, 2006. Disponível em: http://portal.mec.gov.br/seesp/arquivos/ pdf/altashabilidades.pdf. Acesso em 24 out. 2020.

DELOU, C. M. C. Educação do aluno com altas Habilidades/superdotação: legislação e políticas educacionais para a inclusão. In: FLEITH, D. de S. (org). A construção de práticas educacionais para alunos com altas habilidades/superdotação: orientação a professores. Vol. 1. Brasília, MEC/SEESP, 2007.

FLEITH, D. de S., NEVES-PEREIRA, M. S., VIRGOLIM, A. M. R. Toc, toc... plim, plim! lidando com as emoções, brincando com o pensamento através da criatividade. 10 ed. Campinas, SP: Papirus, 2009.

GAMA, M. C. S. S. Parceria entre Família e Escola. In: FLEITH, D. de S. (org). A construção de práticas educacionais para alunos com altas habilidades/superdotação: o aluno e a família. Vol. 3. Brasília, MEC/SEESP, 2007.

GUENTHER, Z. C. Capacidade e talento: um programa para a escola. São Paulo: EPU, 2006.

INEP - Instituto Nacional de Estudos e Pesquisas Educacionais Anísio Teixeira. Sinopses Estatísticas da Educação Básica 2019. Brasília: INEP, 2019. Disponível em: http://portal. inep.gov.br/web/guest/sinopses-estatisticas. Acesso em: 29 out. 2020.

MANZINI, E. J. Análise de entrevista. Marília: ABPEE, 2020.

MOREIRA, L. C. Cursos de licenciatura com bases inclusivas: impressões de alunos com necessidades educacionais especiais e de seus professores. In: MEYRELLES, D. et al. (Org.). Inclusão, práticas pedagógicas e trajetórias de pesquisa. Porto Alegre: Mediação, 2009. p. 261-270.

NEVES-PEREIRA, M. S. Estratégias de Promoção da Criatividade. In: FLEITH, D. de S. (org). A construção de práticas educacionais para alunos com altas habilidades/ superdotação: atividades de estimulação de alunos. Vol. 2. Brasília, MEC/SEESP, 2007.

ORGANIZAÇÃO PAN-AMERICANA DE SAÚDE. Folha informativa COVID-19. 23 out. 2020. Disponível em: https://www.paho.org/pt/covid19. Acesso em: 24 out. 2020.

PARANÁ SEED. Diretrizes Curriculares da Educação Especial para a construção de currículos inclusivos. Curitiba: Secretaria Estadual da Educação, 2006. Disponível em http://www.educadores.diaadia.pr.gov.br/arquivos/File/diretrizes/dce_edespecial.pdf. Acesso em: 24 out. 2020. 
PÉREZ, S. G. P. B. Ofício N 05/2015. Conselho Brasileiro para Superdotação (ConBraSD). Disponível em: http://www.conbrasd.org. Curitiba, 20 maio 2015.

PÉREZ, G. P. B. Políticas públicas para as Altas Habilidades/ Superdotação: incluir ainda é preciso. Revista Educação Especial, v. 27, n. 50, p. 627-640, Santa Maria, set./dez. 2014.

RENZULLI, J. S. Modelo de enriquecimento para toda a escola: Um plano abrangente para o desenvolvimento de talentos e superdotação. Revista Educação Especial, v. 27, n. 50, p. 539- 562, Santa Maria, set./dez. 2014.

RENZUlli, J. S. O Que é Esta Coisa Chamada Superdotação, e Como a Desenvolvemos? Uma retrospectiva de vinte e cinco anos. Porto Alegre - RS, Revista Educação, ano XXVII, n. 1 (52), p. 75 - 131, jan./abr. 2004.

RENZULLI, J. S.; REIS, S. M. The schoolwide enrichment model: a how-to guide for educational excellence. 2. ed. Mansfield Center, CT: Creative Learning Press, 1997.

SABATELLA, M. L. P. Talento e superdotação: problema ou solução? Curitiba: Ibpex, 2008.

SAVATER, F. O valor de educar. São Paulo: Martins Fontes, 2000.

VIRGOLIM, A. M. R. Altas habilidades/superdotação: encorajando potenciais. Brasília, MEC/SEESP, 2007.

VIRGOLIM, A. Altas habilidades/superdotação: um diálogo pedagógico urgente. Curitiba: Intersaberes, 2019.

\section{DAdOS DOS AUTORES}

\section{Michelle Maia Mendonça}

Graduada em Pedagogia pela Universidade Estadual do Norte do Paraná (UENP) e graduada em Ciências Sociais pela Universidade Metropolitana de Santos. Professora na Secretaria de Educação do Estado do Paraná.mi.maia2007@gmail.com

\section{Carla Cristine Tescaro S. Lino}

Doutoranda em Educação no Programa de Pós-Graduação em Educação Universidade Estadual Paulista (UNESP), Marília /SP. Participante do Grupo de Pesquisa em Deficiências Físicas e Sensoriais - DeFSen (UNESP/Marília). carlatescaro@yahoo.com.br 


\section{Diogo Janes Munhoz}

Doutorando em Ciências da Educação na Universidade Columbia, Assunção, Paraguai. Coordenador do Setor de Educação Especial do Núcleo Regional de Educação de Londrina/PR.munhozdiogo@gmail.com

Submetido em: 22-11-2020

Aprovado em: 15-10-2021 